disturbances, in other conditions accumulation of gastric secretions may be of equal or greater significance. The accumulation of highly acidic contents in the stomach may be of significance, partly because it provides a reservoir of material that may reflux. The presence of large volumes of gastric secretions can also trigger vomiting through activation of mucosal nerve receptors ${ }^{8.9}$ as anaesthesia is reversed. Thus, the suppression of secretions by an $\mathrm{H}_{2}$ receptor antagonist may be indicated. ${ }^{\prime}$

\section{Neurogenic ileus}

Abdominal surgery is frequently followed by a period of paralytic ileus, characterized by ineffective peristalsis and atonia which eventually may lead to intestinal obstruction. The most popular explanation is that several factors triggered by surgery might initiate a sympathetic reflex inhibiting gut motility. ${ }^{10}$ However, other factors, such as suppression of cholinergic tone, have also been proposed. "The extent to which anaesthesia and pre- and postoperative medication contribute is an area worth further consideration, particularly because of the welldocumented effects of opioids on motility. ${ }^{7}$

\section{Reversal of nicotinic blockade}

Another gastrointestinal complication that can arise postoperatively is the breakdown of an intestinal anastomosis. ${ }^{12}$ This has been attributed to the effects of anticholinesterases, such as neostigmine, which are used to reverse neuromuscular blockade at the end of surgery. These drugs cause the accumulation of acetylcholine and subsequent stimulation of gut motility, thus potentially producing stress on the suture line. However, consideration of the pharmacology and physiology of the enteric nervous system suggests that several anaesthetic and postoperative medications should prevent this. In vitro studies on human and animal tissues have confirmed these predictions. ${ }^{13}$ Furthermore, in vitro preparations may provide an ideal model system in which to study clinically relevant questions regarding the actions of anaesthetic and analgesic drugs on the gastrointestinal tract.

\section{References}

I Cheeck TG, Gutsche BB. Pulmonary aspiration of gastric contents. In: Shnider SM, Levinson G (Eds.). Anaesthesia For Obstetrics. Baltimore: Williams and Wilkins. 1987; 300-5.

2 Castro $L$ de $P$. Reflux esophagitis as the cause of heartburn in pregnancy. Am J Obstet Gynecol 1967; 98: 1-10.

3 Davison JS, Davison MC, Hay DM. Gastric emptying time in late pregnancy and labour. J Obstet Gynaceol $\mathrm{Br}$ Commonw 1970; 77: 37-41.
4 Davison JS. Gastric emptying in labour. Lancet 1975; II: 227-8.

5 Murray FA, Erskine JP. Fielding J. Gastric secretion in pregnancy. J Obstet Gynaecol Br Commonw 1957; 64: 373.

6 Attia RR, Ebeid. AM, Fischer JE, Gondsozian NG. Mater$\mathrm{nal}, \mathrm{fetal}$ and placental gastrin concentrations. Anaesthesia 1982; 37: 18-21.

7 Nimmo WS, Wilson J, Prescoll LF. Narcotic analgesics and delayed gastric emptying during laoour. Lancet 1975 ; I: $890-3$.

8 Clarke GD, Davison JS. Mucosal receptors in the gastric antrum and small intestine of the rat with afferent fibres in the cervical vagus. J Physiol 1978; 284: 55-67.

9 Davison JS. Response of single vagal afferent fibres to mechanical and chemical stimulation of the gastric and duodenal mucosa in cats. Q J Exp Physiol 1972; 57: 405-6.

10 Neely J, Catchpole B. Ileus: the restoration of alimentary-tract motility by pharmacological means. $\mathrm{Br} \mathrm{J}$ Surg 1971; 58: 21-8.

II Davison JS. Selective damage to cholinergic nerves: possible cause of post-operative ileus. Lancet 1979; 1: 1288.

12 Bell CMA, Lewis CB. Effects of neostigmine on integrity of ileorectal anastomoses. Br Med J 1968; 3: 587-8.

13 Watson N, Davison JS. The effect of anaesthetic agents on neostigmine-induced bowel activity. Can Anaesth Soc J 1984; 31: 567-8.

\section{Pharmacology of agents that affect gastric secretion, emptying, and vomiting}

\section{Gastric emptying}

Delayed gastric emptying is of importance in surgical patients for three reasons: (1) increased risk of aspiration of gastric contents; (2) delayed retum to oral fluids and food; and (3) altered drug absorption. With respect to the last point, approximately 25 per cent of all patients take one or more drugs by the oral route in the perioperative period. The factors which influence gastric emptying in surgical patients are summarized in the Table. Very few actual direct measurements have been carried out in the perioperative period. Several studies on drug absorption 
TABLE Factors which influence gastric emptying rate in the perioperative period ${ }^{3}$

\begin{tabular}{|c|c|c|}
\hline & Increase & Decrease \\
\hline \multicolumn{3}{|l|}{ Physiological factors } \\
\hline Food & & ++ \\
\hline Large volume & ++ & \\
\hline Lying down & & ++ \\
\hline Neuroticism & + & \\
\hline Acid & & + \\
\hline \multicolumn{3}{|l|}{ Pathological factors } \\
\hline Pain & & $+1-$ \\
\hline Pyloric stenosis & & +++ \\
\hline Thyrotoxicosis & + & \\
\hline Hypothyroidism & & + \\
\hline Shock & & + \\
\hline \multicolumn{3}{|c|}{ Pharmacological factors } \\
\hline Opioids & & +++ \\
\hline Atropine-like drugs & & ++ \\
\hline Mist mag trisil & & ++ \\
\hline Metoclopramide & $+t$ & \\
\hline Domperidone & ++ & \\
\hline Cisapride & ++ & \\
\hline Propranolol & + & \\
\hline Alcohol & & ++ \\
\hline
\end{tabular}

(e.g., paracetamol uptake from the small bowel) have been used to estimate indirectly the effect of surgery and anaesthesia. ${ }^{1-3}$

The major cause of delayed gastric emptying before and after surgery is the administration of an opioid analgesic drug. For example, diamorphine can produce a delay of two hours. This delay may be reversed by naloxone or pentazocine, but not by metoclopramide. ${ }^{4}$ Another antidopaminergic, domperidone, acts similarly by increasing acetylcholine release in the gut wall. Both drugs work only on the upper GI tract; they have no effect on gastric secretion. However, delay induced by morphine can be reversed by cisapride, a new gastric prokinetic drug. ${ }^{5}$ This drug increases release of acetylcholine and has no anti-dopaminergic effects (and therefore no central nervous symptoms with higher doses). Gastric secretions are unchanged but lower oesophageal sphincter tone is increased. Gastric emptying is more rapid and mouth to caecum time is shortened. Indications for the drug include gastroparesis, nausea, and vomiting. Side-effects are mild: borborygmi, cramping, diarrhoea, headache, and transient light-headedness. Intravenous injection has produced arterial hypotension.

Before surgery, in the absence of disease which may delay gastric emptying, emptying itself is normal unless the patient has received an opioid. Gastric emptying rate is probably normal immediately after a short anaesthetic, although a more prolonged procedure may result in some delay. Extradural analgesia alone may be associated with a normal pattern of emptying. In adults, the effect of trauma is slight in comparison with that of opioids. Children may be more affected but data are difficult to obtain.

\section{Gastric secretion ${ }^{6}$}

There are receptors for gastrin, histamine and acetylcholine in gastric parietal cells. Function may be inhibited by specific antagonists at each of these receptors. Receptor activation of parietal cell function is mediated by cyclic-AMP-dependent (histamine) and calcium-dependent (cholinergic agents and gastrin) mechanisms. The antisecretory activity of prostaglandins probably reflects interference with histamine activation of adenyl cyclase activity. A third mechanism of inhibition is direct blockade of parietal cell $\mathrm{H}^{+} / \mathrm{K}^{+}$-ATPase by omeprazole. This drug acts on the parietal cell proton pump but is itself destroyed by acid. Therefore, omeprazole must be given in an enteric-coated form or intravenously. The drug is taken up only by "active" parietal cells and is indicated in patients with Zollinger-Ellison syndrome or with ulcers previously refractory to treatment. The need for repeat dosing may limit its usefulness in anaesthesia.

Unfortunately, blockade of gastric secretion is complicated by the fact that gastrin and acetylcholine receptors are present on somatostatin and other cells. In practice, histamine receptor antagonists (cimetidine, ranitidine), prostaglandins (misoprostol, enprostil) and omeprazole are used most commonly to inhibit gastric acid secretion. Subtypes of muscarinic receptors have been identified and selective antagonists, such as pirenzepine, have been used in peptic ulcer disease.

\section{Vomiting}

Nausea and vomiting ${ }^{7}$ can be induced by many physiological and pathological factors. The physiological include: pregnancy, trauma, pain; the pathological include: raised intracranial pressure, labyrinthine, and vestibular disorders. In addition pharmacological effects may induce vomiting by: (1) direct local irritation of the stomach (ipecacuanha, NSAIDs, chloral hydrate, ammonium chloride and other simple salts; (2) central stimulation (opioids, digoxin, levodopa, anaesthetics, bromocryptine); and (3) mixed central and peripheral stimulation (cytotoxic drugs). Propofol produces less nausea and vomiting than thiopentone, and this effect is probably its most desirable characteristic. Nausea and vomiting are controlled by the vomiting centre in the dorso-lateral reticular formation of the medulla. This is affected by impulses from the chemoreceptors and pressure receptors 
in the gut and CNS, peripheral pain receptors, and other neuronal inputs, as well as the chemoreceptor trigger zone. At least some of the synaptic pathways are susceptible to antagonism by centrally acting antimuscarinic drugs.

The chemoreceptor trigger zone has cells which are sensitive to chemical stimuli such as dopamine. The receptors are $D_{2}$ receptors, i.e., they are sensitive to apomorphine and dopaminergic agonists and are antagonized by metoclopramide and sulpimide. Dopamine may act as an inhibitory transmitter in the gastrointestinal tract and may affect peripheral mechanisms concerned with nausea and vomiting.

Anti-emetic drugs may be classified as antimuscarinics (e.g., scopolamine), antidopaminergics (e.g., phenothiazines, butyrophenones, metoclopramide) and others (nabilone, lorazepam, corticosteroids). Antimuscarinics are most useful for motion sickness which is a factor in some cases of perioperative vomiting. Transdermal scopolamine provides up to 90 per cent prevention with acceptable side effects (skin irritation, some hallucinations in young patients, tolerance). Antidopaminergics are most commonly used postoperatively. Metoclopramide 10 to $20 \mathrm{mg}$ IM has been shown to be better than placebo whereas IV administration was no better than placebo. That the drug only acts via the IM route suggests that duration of effect is the determining factor. Droperidol is a very good anti-emetic but can produce hypotension and extrapyramidal effects, with the patient anxious but unable to do anything to counteract the feeling. Additionally, oral dosing is limited by bioavailability.

\section{References}

1 Nimmo WS. Effect of anaesthesia on gastric motility and emptying. Br J Anaesth 1984; 56: 29-36.

2 Walker DAJ. Nimmo WS. New non-invasive methods for measuring gastric emptying. Br J Anaesth 1988; 60: 483-5.

3 Nimmo WS. Drugs, diseases and altered gastric emplying. Clin Pharmacokinet 1976; 1: 189-203.

4 Nimmo WS, Wilson J, Prescott LF. Narcotic analgesics and delayed gastric emptying during labour. Lancet 1975; 1: 890-3.

5 Rowbotham DJR, Nimmo WS. Effect of cisapride on morphine induced delay in gastric emptying. $\mathrm{Br} \mathrm{J}$ Anaesth 1987; 59: 536-9.

6 Soll $A H$. Mechanisms of action of antisecretory agents: studies on isolated canine fundic mucosal cell. $\mathrm{m}$ : Langman MJS (Ed.). Clinical Pharmacology and the Gut. Oxford: SK and F, Oxprint 1985; 13-15.

7 Calvey TN. Hypnotics, sedatives and antiemetics. In Nimmo WS, Smith G (Eds.). Anaesthesia. Oxford: Blackwell, 1989; 22-33

\section{Regurgitation and aspiration in the non- pregnant patient: patho- physiology, incidence, and prophylaxis}

\section{Incidence}

Few studies have examined the incidence of gastrooesophageal reflux associated with anaesthesia. "Silent" (small volume) regurgitation occurs in 4 to 26 per cent of all cases of general anaesthesia, the higher incidence reported in older studies. ${ }^{1-3}$ More recently, Blitt et al. reviewed 734 general anaesthetics and found 68 (nine per cent) episodes of regurgitation, six of which led to aspiration. Only one of these patients developed pulmonary complications postoperatively, but it was not possible to "definitely relate the pulmonary complication to the aspiration." Carlsson et al. ${ }^{5}$ found a 20 per cent incidence of regurgitation of acidic material in the pharynx of patients undergoing emergency laparoscopy. No correlation of this finding with either pulmonary aspiration or pneumonitis was given. The clinical significance of silent regurgitation associated with general anaesthesia remains to be established.

Three recent studies tend to confirm that the incidence of aspiration pneumonitis, and related mortality, is low. Tiret et al. ${ }^{6}$ reported 27 cases of aspiration of gastric contents in a review of 198,103 anaesthetics given in France, an incidence of $1.4 / 10,000$. These 27 cases of aspiration, of which 13 occurred during the postanaesthetic period, led to four deaths and left two patients comatose. In Canada, Cohen er al. ${ }^{7}$ reported 34 and 38 cases of aspiration of gastric contents in a study of 112,721 anaesthetics during the periods extending from 1975 to 1978 and from 1979 to 1983 , respectively, for a mean stable incidence of 6.4/10,000. In Sweden, Olsson et $a l .^{8}$ reviewed 185,358 computer-based anaesthetic records (where aspiration could be specifically recorded) and found an incidence of 4.7 aspirations in 10,000 anaesthetics. Aspiration led to radiologically confirmed pneumonitis in 47 per cent of cases and to death in 0.2 cases per 10,000 anaesthetics.

\section{Prevention of reflux in the normal individual}

The main factor preventing gastrooesophageal reflux is the lower oesophageal sphincter (LOS), a physiological 